\title{
Management of giant condyloma acuminatum on HIVIAIDS patient with limited healthcare facilities
}

\author{
Stanley Ariestia Tanjaya \\ Flora Debby Ngolo \\ Wahyu Setyo Nugroho
}

Department of Obstetrics and Gynecology, Paniai General Hospital, Paniai, Papua, Indonesia
Cite this article:

Tanjaya SA, Ngolo FD, Nugroho WS.

Management of giant condyloma acuminatum on HIVIAIDS patient with limited healthcare facilities. Neurologico Spinale Medico Chirurgico. 2020.3(3): I I 2-I I 7.

DOI: I0.36444/nsmc.v3i3.I28

Corresponding author:

Stanley Ariestia Tanjaya

Paniai General Hospital

Jalan Raya Madi km. 7, Paniai

Papua, Indonesia

Orcid ID: 0000-000I-7853-174X

stanley050490@gmail.com

\begin{abstract}
Giant Condyloma Acuminatum (GCA) or Buschke-Lowenstein Tumour (BLT) is a unique variant of condyloma acuminatum. The incidence of this disease tends to increase due to the increasing prevalence of Human Immunodeficiency Virus (HIV) infection. Until now, there is no therapeutic guideline for GCA, and many therapeutic options are not available for one in limited healthcare facilities. We present one case of GCA in an HIVpositive woman treated in health centers with limited facilities in a rural area. We treat the patient by doing sitz bath with povidone-iodine $1 \%$, simple excision with electrocautery for the tumour, adequate analgetics, regular wound care and zinc supplementation acts as immunotherapy. Complications of wound infection by candida caused the lengthy hospitalization of the patient. After discharge, the patient came for control every week; no other lump arises again, and the wound was getting better. A combination of conservative and surgical treatment followed by regular wound care can lead to a good result in the GCA case, even with minimal healthcare facilities.
\end{abstract}

Keywords: Limited healthcare facilities, preoperative sitz-bath, simple excision, regular wound care

\section{Introduction}

Giant Condyloma Acuminatum (GCA) or Buschke-Lowenstein Tumour (BLT) is a unique variant of condyloma acuminatum. It usually appears in the form of a cauliflower tumour around the anogenital area with growth characteristic of aggressively pushing the dermal tissue below. ${ }^{1-3}$ The prevalence of this tumour in the general population is about $0.1 \%$. At present, GCA cases' incidence tends to increase due to the increased rate of Human Immunodeficiency Virus (HIV) infection. GCA is more common in males than females, with a ratio of 2.3:1. In women, GCA appears more frequently in the area of vulva and sometimes in the perianal site. Histologically, GCA is similar to ordinary condyloma acuminatum, but GCA has an aggressive and destructive nature that is not found in a usual case of condyloma acuminatum. ${ }^{1,2,4}$ Only a few instances of condyloma acuminatum develop into GCA, with the most critical risk factors are immunodeficiency and anogenital sexual intercourse with multiple partners. $^{5}$ 
Although GCA cases include benign tumours, often in therapy, there are difficulties due to the size of the tumour, local invasion, and the increased rate of recurrence. Until now, there is no specific therapy guideline for GCA. Many treatment options, both medically and surgically, can be found in the literature with different results. ${ }^{6}$ Many therapeutic options mentioned in the research require modalities that are often not available in rural areas.

We present one case of GCA in HIV-positive women treated in health centers with limited healthcare facilities in a rural area.

\section{Case report}

A twenty-eight years old woman came with a complaint of a pubic lump for six months, a lump resembling a cauliflower, large, flesh-colored, easily bleeding, and foul-smelling. The lumps initially appeared small, then grew more prominent, reaching the current size within four months. Pain was felt, especially when sitting. The patient admitted a history of multiple sex partners.

On physical examination, we found multiple verrucous tumours resembling cauliflower shape, blackish-grey with white spots, foulsmelling, easily bleeding with a size of $20 \times 14 \mathrm{~cm}$ and a thickness of 5 $\mathrm{cm}$ covering the mons pubis area, labia majora, labia minora, vagina, inguinal and perianal.

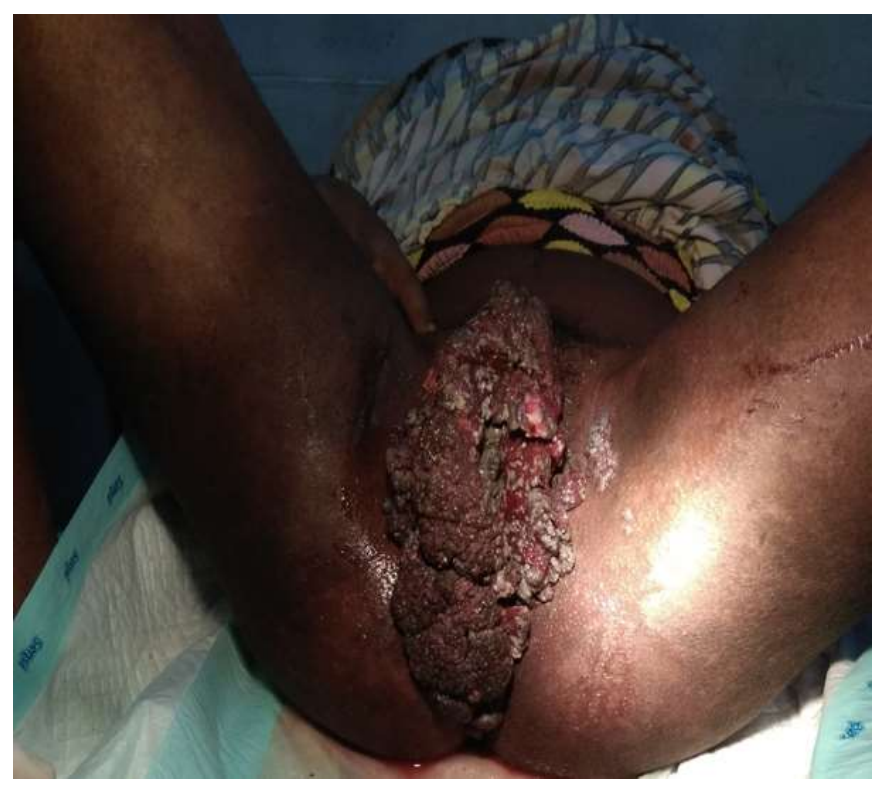

Figure 1. Early condition at admission. On genital examination, there were verrucous tumours resembling cauliflower, multiple, blackish-grey with white spots, foul-smelling, easily bleeding with a size of $20 x 14 \mathrm{~cm}$ with a thickness of

$5 \mathrm{~cm}$ covering the mons pubis area, labia majora, labia minora, vagina, inguinal and perianal
Laboratory test results showed a haemoglobin level of $9.0 \mathrm{~g} /$ $\mathrm{dL}$, and HIV positive. Incisional biopsy and histopathological examination result showed skin tissue with hyperkeratosis, acanthosis, and papillomatosis. Epithelial cells with koilocyte cells, epithelial cells are regularly arranged with an intact basal membrane. There was no malignancy sign. Conclusion of histopathological examination results were suitable for the description of condyloma acuminatum.

Management of this case includes the sitz bath with povidoneiodine $1 \%$ twice a day for seven days before surgery. Because there is no malignancy sign and basal membrane still intact, the surgery method we choose was excision of the skin with electrocautery to the extent of the tumour in labia majora, labia minora, around the vulva, and perianal area. After the surgery, we inject 2 gram ceftriaxone intravenous (IV) once daily, 500 milligrams metronidazole IV drip three times daily. For the analgesics drug, we consulted the anesthesiologist. The patient was given 0.8 milligrams morphine IV drip per hour, 30 milligrams ketorolac IV three times daily, and 500 milligrams paracetamol tablet four times daily. The administration of metronidazole drip was stopped on the $11^{\text {th }}$ day postoperatively. Antibiotic injection of ceftriaxone was replaced with oral cefadroxil 500 milligrams twice daily on the $16^{\text {th }}$ day postoperatively. The patient was also given immunomodulators with zinc tablet preparation at a dose of $10 \mathrm{mg} / \mathrm{kg} / \mathrm{day}$. Wound care was carried out every other day with gentamycin ointment and sufratulle, then the wound was covered with moist gauze.

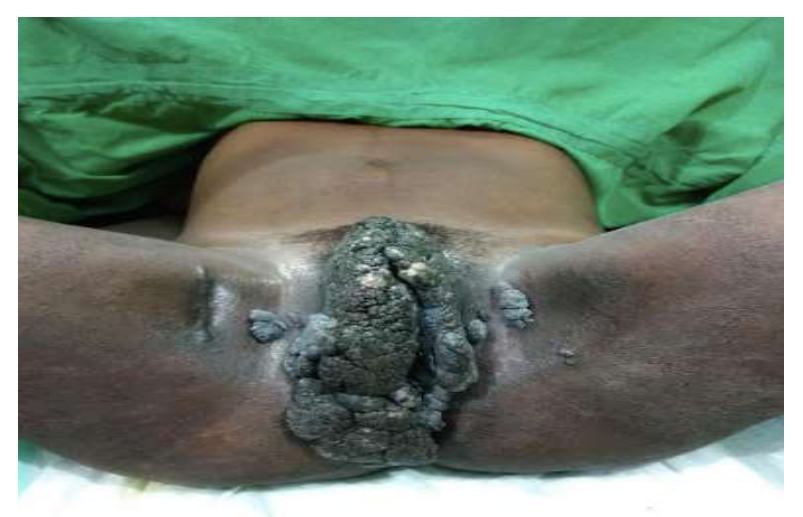

Figure 2. Tumour condition after sitz bath with povidone-iodine 0.05\%

From the follow-up, there was an infection in the surgical wound and then improved during treatment. There was a complication encountered in the form of vaginal discharge. We did a vaginal swab then examined the vaginal discharge, and the result was candida. We gave additional intravaginal nystatin 100.000 IU to treat the candida infection. 
The patient was discharged on the $41^{\text {st }}$ day postoperatively with an excellent general condition; dry wounds and granulation were seen. The patient came to control every week, and we did not find any signs of recurrence. The patient was recommended to routinely control every week until the third month postoperatively or suddenly if a lump arises again.

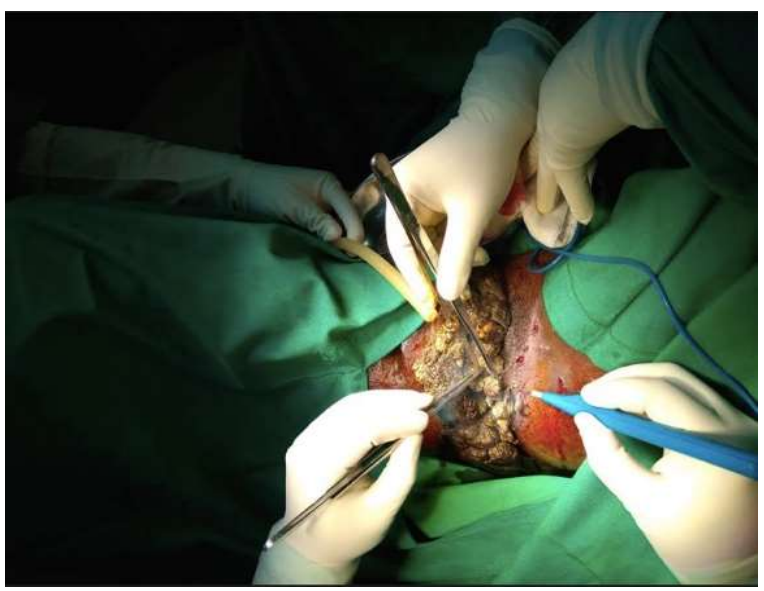

Figure 3. Surgery treatment with electrocauter

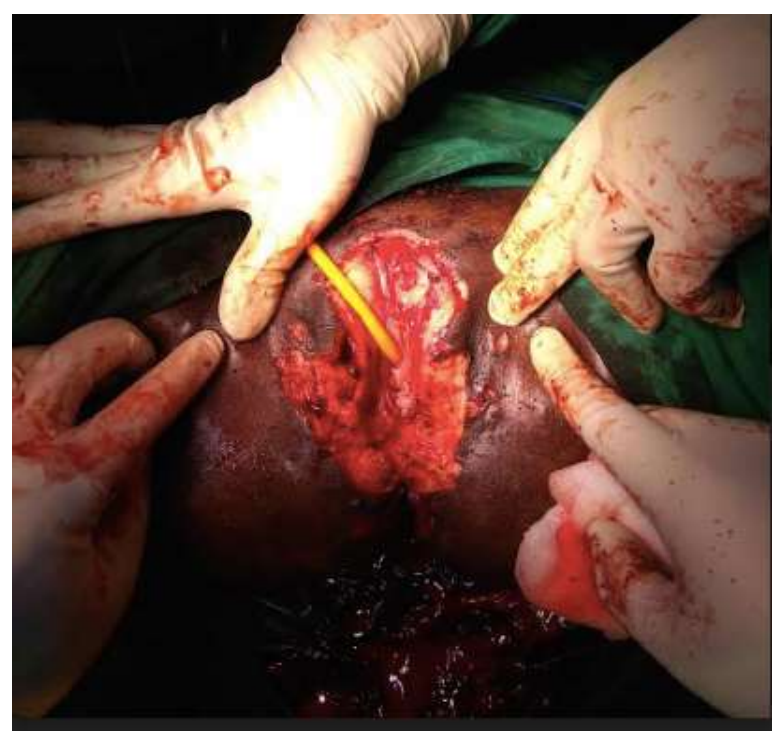

Figure 4. Condition after surgery

\section{Discussion}

Giant condyloma acuminatum (GCA) is a local mass with a slow, destructive, and large invasive growth pattern. Clinically, the mass is exophytic, with the shape of a cauliflower, which has a benign appearance on histopathology but can invade local tissue. ${ }^{1}$ Giant condyloma acuminatum is a sexually transmitted disease that very rarely occurs. The incidence of this tumour is only $0.1 \%$ of the entire population. ${ }^{2}$ A common problem for this case is that the large size of the tumour shows aggressive characteristics, with a high recurrence rate and has significant potential for malignant transformation.

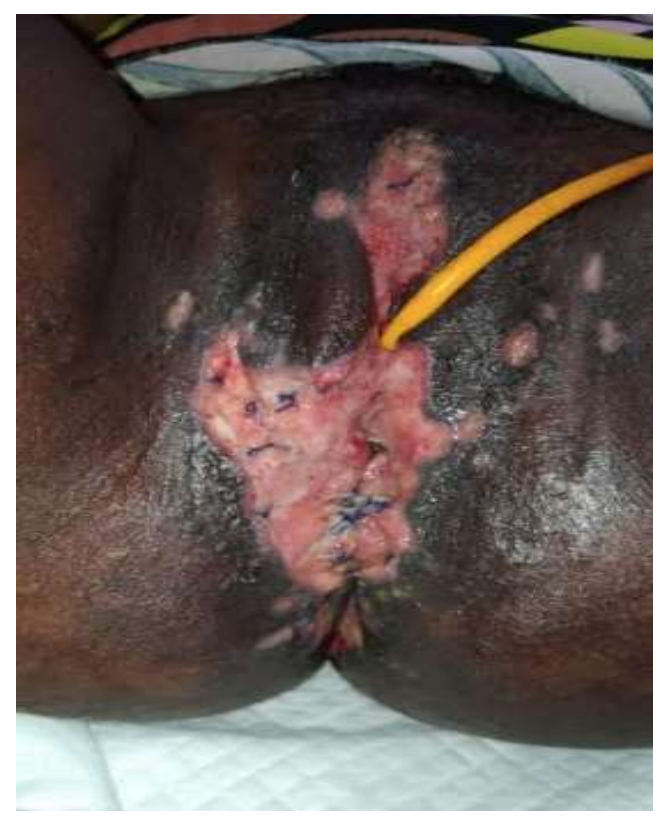

Figure 5. Wound appearance two weeks after surgery

While GCA is histologically a benign tumour, which macroscopically resembles condyloma acuminatum, it may be difficult to distinguish between these two conditions, especially in the early stages of the disease. ${ }^{7,8,9}$ Like ordinary condyloma acuminatum, Human Papilloma Virus (HPV) is the leading cause of this disease, especially types 6 and 11, while HPV types 16 and 18 are less frequent causes. The decline in the immune system is one of the contributing factors of the disease. ${ }^{2}$ In each case of GCA, the patient's immunological status must be examined. Serological testing for sexually transmitted infections, including HIV, syphilis, hepatitis B, and hepatitis $\mathrm{C}$ is mandatory. ${ }^{6}$ In this case report, HIV infection caused a more severe disease of the human papillomavirus so that the lesions became more prominent and more invasive.

Aside from the consequences of HIV infection, other conditions, such as organ transplantation, have been reported in cases of GCA. Hyun et al., ${ }^{7}$ reported a 31-year-old male patient complained of pain in the anal area approximately one month after undergoing an organ transplant. After the procedure, the patient was given $9 \mathrm{mg} / \mathrm{kgBW}$ ATG (Anti Thymocyte Globulin) for immunosuppressants. The patient is not married and had no history of having sexual activities. HIV screening tests and other sexually transmitted diseases were negative. 
Whereas in this case report, there was a history of multiple sex partners.

Symptoms felt by patients usually last long, because this disease develops slowly. In this case, the patient complained of feeling uncomfortable (gagging) in the genitals for six months before the examination. Lumps initially appeared small, then grew bigger and longer, reaching the current size within four months. Pain was felt, especially when sitting. In a case report published by Sandhu et al., ${ }^{8}$ the symptoms felt by the patients were first complained about 20 years before the examination. Patients complained of pea-sized lesions that grew larger slowly, up to one week before the exam, where the patients had been bleeding in the wound, and a discharge of foul-smelling fluid from the lesion was seen.

The pathogenesis of this infection is strongly influenced by host lymphocytes and Natural Killer (NK) cells whose activities can be supported by interferon. ${ }^{6}$ After invading cells, the virus will invade cells in the basal layer. The virus will be in a subclinical state for approximately three months. Cells then replicate in basal cells, which actively divide and cause interference in cell cycle control. Viral replication still occurs in the surface cell layer. Surface cells containing HPV will exfoliate and become a source of transmission. In a healthy state, the host immune system can eliminate the virus through interleukin, which increases cellular immune responses and interferon, both can inhibit viral replication. This mechanism allows the transmission of spontaneous regression in the initial lesion. In situations where the body's immune system decreases, the risk of HPV infection will be higher with manifestations of more giant, multifocal, and dysplastic lesion. ${ }^{8}$ The progression of benign condyloma acuminatum to GCA may be caused by the oncogenic potential of HPV type 6 or 11 as the leading cause. Jose et al., ${ }^{9}$ showed that it remains unclear whether the viral or host risk factors have more contribution to the transformation of HPV type 6 or 11 to become oncogenic. Furthermore, it is believed that free oxygen radicals play essential roles in the oncogenic transformation of this disease.

Management of GCA can be classified into three types: topical therapy, tumour removal (surgery), and immunotherapy. However, there is no gold standard for treating this rare disease. Treatment depends on the size of the lesion, the depth, location, previous therapy, as well as the operator's experience and skills. ${ }^{7}$ Iodophor preparations are usually used in the medical field for skin antiseptic before percutaneous and surgical procedures are performed. The commonly used iodophor is povidone-iodine. Povidone-iodine kills microorganisms, including bacteria, viruses, yeast, fungi, and protozoa. ${ }^{10}$ Management of this case was initiated by sitz bath with povidone-iodine twice a day for seven days before surgery.

Mentioned in the research conducted by Caprioti et al., ${ }^{10}$ this new povidone-iodine formulation appears to be an effective, safe, and well-tolerated treatment in cases of warts in children and adults. This formulation fights HPV infection with an unspecified mechanism of action. The electrons within povidone-iodine will inhibit protein synthesis, cellular respiration, disrupt membranes, and nucleic acid denaturation in the HPV virus and virus-infected host cells.

In this patient, after sitz bath with povidone-iodine concentration $\pm 0.5 \%(500 \mathrm{~mL}$ of $10 \%$ povidone-iodine solution dissolved in $10 \mathrm{~L}$ water) for seven days, the condyloma mass in the patient appears to be drier, not fragile, and not easily bleed. This condition is very beneficial during the surgical process

The standard clinical treatment of anogenital warts is generally conservative; however, in extreme cases, conventional therapy is insufficient, and surgical excision is needed. The radical excision of the large anogenital lesion is usually recommended as the first-line therapy.

In this case, a simple surgery action was decided because of the limitations of hospital facilities and the patient and her family refuse to be reffered to better healthcare facility. After got the histopathology result that the tumour showed no malignancy sign and the basal membrane is still intact, we decide to do the excision of the skin with electrocautery to the extent of the tumour in the area of the labia majora, labia minora, around the vulva, and perianal. Hyun et al., ${ }^{7}$ suggested that simple excision had been reported as an adequate therapeutic strategy in some cases of GCA without evidence of disease recurrence. Simple excision is also supported by Coreia's study, which suggested that minimally invasive techniques such as electrocautery can be safer and more cost-effective than surgery. However, these techniques limited only to noninvasive tumour cases and can be considered a good treatment option with a good response. The weakness of this technique is that patients usually have moderate depigmentation and few superficial atrophic scars. . $^{3,6,8}$

After surgery, we administered analgesics and antibiotics as prophylaxis for postoperative infections. In the acute phase, the first three days, the patient was given a $2 \mathrm{mg}$ morphine loading dose followed by $0.8 \mathrm{mg} /$ hour plus an intravenous $30 \mathrm{mg}$ of ketorolac preparations every 8 hours and oral paracetamol at a dose of 500 milligrams every 6 hours. By giving the analgesic, the patient became comfortable, and the pain felt was minimal. General anesthesia, regional analgesia, and infection control are priorities in all surgical treatments. Adequate local anesthesia and prescription of mild analgesics will minimize discomfort during the procedure and wound 
healing. ${ }^{11,12}$ Because of limited local anesthesia agents we had in our healthcare facilities, we optimize the analgesic drug use to comfort the patient while in treatment. We give two types of broadspectrum antibiotics considering the patient's low immune status caused by HIV infection. Unfortunately, we cannot do bacterial culture and sensitivity tests in our hospital, so we choose two empirical broadspectrum antibiotics, ceftriaxone, and metronidazole, to cover gram-negative, gram-positive, and anaerobic bacterial infection that may infect the postoperative wound.

We had to do regular wound care every other day because there is excessive debris in the postoperative wound and minimalized vaginal discharge that can interrupt the skin tissue's granulation process. The current principal for topical wound management is to eliminate the things that can inhibit wound healing by keeping the wound clean, to retain moisture, and protect the wound surface. ${ }^{13} \mathrm{We}$ usually start wound care by rinse the wound with natrium chloride $0.9 \%$ solution, then disinfect the wound with a povidone-iodine solution; we also do the vaginal hygiene procedure to remove excessive vaginal discharge. After that, we remove the necrotic tissues and debris that occurred, and then we give topical antibiotic ointment and cover the wound with sufratulle before moist dressing was applied. Topical antibiotics are accepted as a safe and effective treatment for the treatment of wounds because it can reduce the possibility of temporary infections and keep the wound environment moisturized. ${ }^{13}$ In this case, moist gauze was also provided in addition to wound care to maintain moisture and protect the wound surface. In a study conducted by Clare et al., ${ }^{14}$ It was concluded that the risk of infection after surgery was reduced using topical antibiotics compared to the group given antiseptics or control groups. Topical antibiotics that can be used to accelerate wound healing in America and Europe, including one of them are gentamicin (Garamycin). ${ }^{13,15}$

This patient had vaginal discharge caused by candida, which could disrupt the healing process of the wound. For this reason, a dose of $1000 \mathrm{mIU}$ nystatin was administered intravenously to the patient to treat the cause, so that wound healing was not disturbed by fungal infections.

In this case, the patient is known to be HIV positive. Antiretroviral therapy was not administered yet because the patient's adherence to taking medicine is still not good. We decided to give zinc tablets at $10 \mathrm{mg} / \mathrm{kg} /$ day as an immunomodulators. Zinc is an essential element for immune function. Zinc also has unique antiviral activity by crossing the double helix of viral DNA, thus inhibiting viral replication; and then, by deactivating viral surface glycoproteins to interfere with penetration into susceptible host cells. Zinc deficiency has been shown to cause decreased immunity to skin infections. ${ }^{17,18}$

HIV causes immune system depression by mainly affecting $T$ cells responsible for the body's ability to defend itself against foreign organisms. In HIV infection, zinc plays a unique role as an antioxidant, immune modulator, and maybe a direct antiviral agent. In-vitro zinc is found to inhibit cell death mediated by tumour necrosis factor, a cytokine associated with cell apoptosis and wasting syndrome in HIV. ${ }^{18}$

Zinc can also be used for several dermatological conditions, including warts due to modulation actions on the function of macrophages and neutrophils, natural killers of cell or phagocytic activity, and various inflammatory cytokines. The administration of oral zinc with a dose of $10 \mathrm{mg} / \mathrm{kg} /$ day for two months is a modality effective for cases of recalcitrant warts. In a study conducted by Mrinal et al., ${ }^{19}$ mentioned that oral sulfate zinc (10 mg/kg/day) given for two months at warts produced complete cleansing in $61 \%$ of patients in one month and $87 \%$ of patients after two months of therapy.

\section{Conclusion}

Treatment of GCA cases in HIV positive patients with limited healthcare facilities combines medication and surgical intervention. The preoperative sitz bath shows promising results in the tumour and makes fewer surgical complications. Fungal infection complicates the surgical wound healing, and routine wound care must be done every other day. The host immune factor also plays an important role in disease progression. Regular checkup should be made to make sure there's no recurrence of the tumour.

\section{References}

1. Erkek E, Basar H, Bozdogan O, et al. Giant condyloma acuminata of Buschke-Löwenstein: successful treatment with a combination of surgical excision, oral acitretin and topical imiquimod. Clin Exp Dermatol. 2009;34(3):366-368. DOI: $\quad$ 10.1111/j.13652230.2008.02938.x

2. Papiu HS, Dumnici A, Olariu T, et al. Perianal giant condyloma acuminatum (Buschke-Löwenstein tumor). Case report and review of the literature. Chirurgia (Bucur). 2011;106(4):535-539. Available from: https://pubmed.ncbi.nlm.nih.gov/21991883/

3. Zekan J, Petrovic D, El-Safadi S, et al. A surgical approach to giant condyloma (Buschke-Löwenstein tumour) with underlying superficial vulvar carcinoma: A case report. Oncol Lett. 2013;5(2):541-543. DOI: 10.3892/ol.2012.1027 
4. Lévy A, Lebbe C. Prise en charge des tumeurs de Buschke-Löwenstein. Annales d'Urologie. $2006 \quad$ June;40(3):175-178. DOI:10.1016/j.anuro.2006.02.002

5. Virgilio E, Balducci G, Mercantini P, et al. Perianal giant condyloma acuminatum of Buschke-Loewenstein: a carcinoma-like condyloma or a condyloma-like carcinoma?. ANZ Journal of Surgery. 2015; 85(5):394-395. DOI:10.1111/ans.12913

6. Correia E, Santos A. Buschke-Löwenstein Tumour: Successful Treatment with Minimally Invasive Techniques. Case Rep Dermatol Med. 2015;2015:651703. DOI: 10.1155/2015/651703

7. Hyun JS, Kim GB, Choi BS, et al. Giant anal condyloma (giant condyloma acuminatum of anus) after allogeneic bone marrow transplantation associated with human papillomavirus: a case report. Journal of Medical Case Reports 2015;9:9. DOI:10.1186/1752-19479-9

8. Sandhu R, Min Z, Bhanot N. A Gigantic Anogenital Lesion: Buschke Lowenstein Tumour. Case Reports in Dermatological Medicine. 2014:1-3. DOI:10.1155/2014/650714

9. Martin JM, Molina I, Monteagudo C, et al. Buschke-Lowenstein tumour. $J$ Dermatol Case Rep. 2008;2(4):60-62. DOI: 10.3315/jdcr.2008.1019

10. Capriotti K, Stewart KP, Pelletier JS, et al. A Novel Topical $2 \%$ Povidone-Iodine Solution for the Treatment of Common Warts: A Randomized, Double-Blind, Vehicle-Controlled Trial. Dermatol Ther (Heidelb). 2015;5:247-252. DOI:10.1007/s13555-015-0086-1

11. Ghaemmaghami F, Nazari Z, Mehrdad N. Female genital warts. Asian Pacific Journal of Cancer Prevention: APJCP. 2007;8(3):339-347. Available from: http://europepmc.org/article/med/18159964

12. Costa MTF, Gomes AD, Santos PB, et al. Giant Condyloma Acuminatum: Report of Surgical Treatment amd Evolution of Healing.
J bras Doencas Sex Transm. 2015;27(1-2):48-53. DOI :10.5533/DST2177-8264-2015271-209

13. Trookman NS, Rizer RL, Weber T. Treatment of minor wounds from dermatologic procedures: a comparison of three topical wound care ointments using a laser wound model. Journal of the American Academy of Dermatology. 2011; 64(3 Suppl):S8-15. DOI: 10.1016/j.jaad.2010.11.011.

14. Heal CF, Banks JL, Lepper PD, et al. Topical antibiotics for preventing surgical site infection in wounds healing by primary intention. Cochrane Database of Systematic Reviews. 2016; Issue 11. Art. No.: CD011426. DOI: 10.1002/14651858.CD011426.pub2.

15. Diehr S, Hamp A, Jamieson B, et al. Clinical inquiries. Do topical antibiotics improve wound healing?. The Journal of family practice. 2007; 56: 140-4. Available from: https://pubmed.ncbi.nlm.nih.gov/17270122/

16. Lotan AM, Lysy I, Weiner-Well Y, et al. Topical Nystatin Treatment for Candida Infection Following Wound Reconstruction. Wounds. 2018; 30(2): 41-44. Available from : https://pubmed.ncbi.nlm.nih.gov/29481329/

17. Sinha S, Relhan V, Garg VK. Immunomodulators in warts: Unexplored or ineffective?. Indian J Dermatol .2015; 60: 118-29. DOI: $10.4103 / 0019-5154.152502$

18. Asemota EA, Okafor IM, Okoriwu HU, et al. Zinc, copper, CD4 T-cell count and some hematological parameters of HIV-infected subjects in Southern Nigeria. Integr Med Res. 2018; 7(1): 53-60. DOI: 10.1016/j.imr.2018.01.008

19. Gupta M, Mahajan VK, Mehta KS, et al. Zinc Therapy in Dermatology: A Review. Dermatology Research and Practice. 2014; 709152: 1-11. DOI:10.1155/2014/709152 